\title{
Teething in infants-Knowledge and attitude of traditional birth attendants in Ibadan, Nigeria
}

\author{
Olubunmi Olusola Bankole ${ }^{1^{*}}$, Julianah Obontu Taiwo $^{2}$, Adelegan Michael Adesakin $^{3}$ \\ ${ }^{1}$ Department of Child Oral Health, University of Ibadan, Ibadan, Nigeria; \\ *Corresponding Author: bumbank2002@yahoo.com \\ ${ }^{2}$ Department of Community Dentistry and Periodontology, University of Ibadan, Ibadan, Nigeria \\ ${ }^{3}$ Department of Community Dentistry and Periodontology, University College Hospital, Ibadan, Nigeria
}

Received 27 June 2013; revised 27 July 2013; accepted 12 August 2013

Copyright (c) 2013 Olubunmi Olusola Bankole et al. This is an open access article distributed under the Creative Commons Attribution License, which permits unrestricted use, distribution, and reproduction in any medium, provided the original work is properly cited.

\section{ABSTRACT}

Introduction: Misconceptions are associated with the teething process in Nigeria and is often blamed for symptoms in infants. A horrendous incident occurred in Nigeria in 2008 which recorded 84 infant deaths due to consumption of adulterated teething syrup to prevent teething problems. In the quest to engage the populace, particularly mothers, in health education to change this erroneous mindset about teething, it will be necessary and more cost effective to involve Traditional Birth Attendants (TBA's) who can be invaluable in assisting to dispel myths associated teething as they live and work among the local populace and many times give counsel to mothers. Aim: To assess the attitude and beliefs of TBA's in Ibadan, to teething in infants. Methods: $A$ cross sectional survey was conducted among TBA's in Ibadan, Nigeria. A thirteen item interviewer administered questionnaire was distributed to all 163 TBA's in the five urban local government areas who agreed to be part of the study. Results: Over half of the respondents (59.5\%) and $(55.8 \%)$ associated the teething process with fever and diarrhea respectively. Other beliefs included boils (49.1\%), loss of appetite (48.5\%), weight loss (44.2\%), and sleeplessness (42.3\%). A greater proportion of the older and less educated TBA's associated teething with fever, diarrhea, boils, loss of appetite and weight loss. The respondents would advise analgesics $(55.8 \%)$, teething powder (67.5\%), antibiotics (12.3\%), concoctions (4.3\%) and sedatives (4.3\%) as teething remedies. There was a greater tendency for less educated TBA's to advise the use of concoctions and antibiotics. Conclusion: The study reveals grave misconceptions among TBA's who in developing countries like Nigeria give counsel to mothers in the various communities. There is an urgent need for health education to the TBA's particularly the older and less educated ones.

Keywords: Knowledge; Attitude; Traditional Birth Attendants; Teething; Infants

\section{INTRODUCTION}

Teething is a natural physiological process that all children experience and generally commences from 6 months to about 3 years of age [1].

Though the timing as well as process of teething is a joyful expectation of parents, misconceptions are often associated with the process. The belief that teething was a deadly disease was widely accepted until the late $19^{\text {th }}$ century. Hippocrates claimed that children experiencing teething suffered from itching gums, fever, convulsions and diarrhea, especially when cutting their canines [2]. In 1839, 5016 child deaths in England and Wales were attributed to teething [3].

The experience of Turkish parents about their infants teething showed that $78.8 \%$ of symptoms observed in their children such as increased in biting, irritability and fever was attributed to teething [4]. Owais et al., (2010) [5] in a study in Jordan among 1500 parents attending maternity and health centers revealed that about $75 \%$ of participants incorrectly attributed fever, diarrhea and sleep disturbances to teething.

In Nigeria, 58\% of ethnic rural dwellers in Ibadan, Nigeria attributed various ailments such as fever, diarrhoea and conjunctivitis to teething [6]. Other studies revealed 
that the parents or caregivers thought that fever in their children meant teething problems $[7,8]$.

Similarly, in a study on teething problems and parental beliefs, it was stated that mothers believed teething should be accompanied with symptoms such as fever (42.1\%), diarrhea (13.9\%) and vomiting (0.6\%) [9].

The inherent danger is that mothers may not seek consultation for common childhood ailments during the teething period and may resort to self medication [10,11]. A horrendous incident occurred in Nigeria in 2008 which recorded 84 infant deaths due to consumption of adulterated teething syrup "my pickin" to prevent teething problems [12].

In the quest to engage the populace particularly mothers in health education to change this mindset, it will be necessary and more cost effective to involve Traditional Birth Attendants (TBA's) (also known as traditional midwives), who live and work among the local populace and many times give counsel to nursing mothers. Many studies have established the important role of TBA's in educating the populace particularly mothers regarding immunization, obstetric and gynecological issues [1316].

The majority of deliveries in developing countries like Nigeria don't take place in registered hospitals and are handled by trained/untrained attendants [17]. Considering the influence within their communities, TBAs should be able to convey health messages in a culturally acceptable way. However, to ensure the correct transfer of information, it is pertinent that baseline data of their knowledge, attitudes and practices should be explored. It is therefore the aim of this study to determine the knowledge, attitude and practices of TBAs towards infant teething.

\section{METHODOLOGY}

A descriptive cross sectional study was carried out among TBA's in Ibadan, the capital of Oyo State, a city in southwestern Nigeria. Ibadan is strategic and the third largest metropolitan town by population in Nigeria, with a population of over 2.5 million people [18]. Traditional Birth Attendants in all the urban local government areas (Ibadan North, North West, South West, South East and North East Local Governments Areas) participated in the study.

All registered TBA's with the Ministry of Health [19] who agreed to be part of the study were interviewed by four trained research assistants. The instrument of measure consisted of a 13-item semi structured questionnaire translated into the local Yoruba language.

Information obtained from the TBA's included basic demographic data, symptoms they felt were associated with the teething process and remedies they would proffer.

Permission was obtained from of the Local Government Authorities and informed consent was taken from the respondents before commencement of the study. Study was approved by the Ethical Review Committee, Ministry of Health, Oyo State of Nigeria.

Data was collated and computer data entry was carried out. Data was analyzed using the Statistical package SPSS 15. Frequency tables were generated and cross tabulations were made where necessary. Association between variables could not be determined as there were multiple responses

\section{RESULTS}

One hundred and sixty three TBAs were interviewed with age range of 27 - 75 years with a mean age of 47 years $(\mathrm{SD}=10.82$ years). Seventy eight $(47.9 \%)$ participants were above 50 years of age while 48 (29.4\%) fell in the 40 - 49 year old bracket. There was a female preponderance of $95.5 \%$. Majority 80 (49.1\%) had secondary education, a quarter (24.5\%) had attended only primary school, whist 16 (9.8\%) were illiterates. Many 75 (46.0\%) had been in practice for at less than 10 years with about a fifth (19.0\%) having practiced for more than 20 years (Table $\mathbf{1}$ ).

Majority of the TBAs (55.0\%) reported that the range of timing of eruption of babies teeth was between 6 - 8 months and stated that this period was the commencement of myriads of teething symptoms in infants (Figure 1).

Many of the TBA's had various beliefs and attitudes to teething with 97 (59.5\%), 91 (55.8 \%) and 80 (49.1\%) associating teething with fever, diarrhea and boils respectively. Over two fifths (44.2\%) believed the teething process caused weight loss in children (Figure 2).

A greater proportion of the respondents over 40 years of age in comparison to the younger ones associated teething with fever, diarrhea, loss of appetite, sleeplessness weight loss, boils and excessive thirst (Figure 3).

Also, there was a greater tendency for the less educated TBAs to associate teething with fever, diarrhea, weight loss, loss of appetite and boils (Figure 4).

Recommendations made by the TBAs included giving antibiotics 20 (12.3\%), teething powder/syrup 91 (55.8\%), analgesics 110 (67.6\%), traditional concoctions 7 (4.3\%) and sedatives 7 (4.3\%) (Figure 5).

Figure 6 illustrates treatment recommended by the TBAs according to their ages. Older TBAs are more likely to recommend analgesics and antibiotics.

The influence of educational status when recommending treatment is shown in Figure 7. There was a greater tendency of those with less education to recommend concoctions, sedatives and antibiotics.

A greater proportion of those with over 10 years of professional experience would prescribe analgesics, antibiotics and concoctions (Table 2). 
Table 1. Socio-demographic characteristics of the traditional birth attendants.

\begin{tabular}{ccc}
\hline Characteristics of the TBAs & Frequency & \% \\
\hline Age group (years) & (n = 163) & \\
$<40$ & 37 & 22.7 \\
$40-49$ & 48 & 29.4 \\
50 and above & 78 & 47.9 \\
Sex & & \\
Male & 7 & 4.3 \\
Female & 156 & 95.7 \\
Education & & \\
No formal education & 27 & 16.6 \\
Primary & 40 & 24.5 \\
Secondary & 80 & 49.1 \\
Post Secondary & 16 & 9.8 \\
Years of experience & & \\
1 - 10 & 75 & 46.0 \\
11 - 20 & 57 & 19.0 \\
Above 20 & 31 &
\end{tabular}

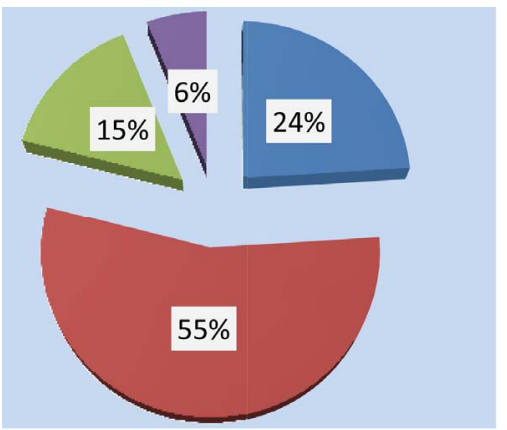

3-5months

6-8 months

9-11 months

12 months and above

Figure 1. Timing of eruption of babies teeth as perceived by the TBAs.

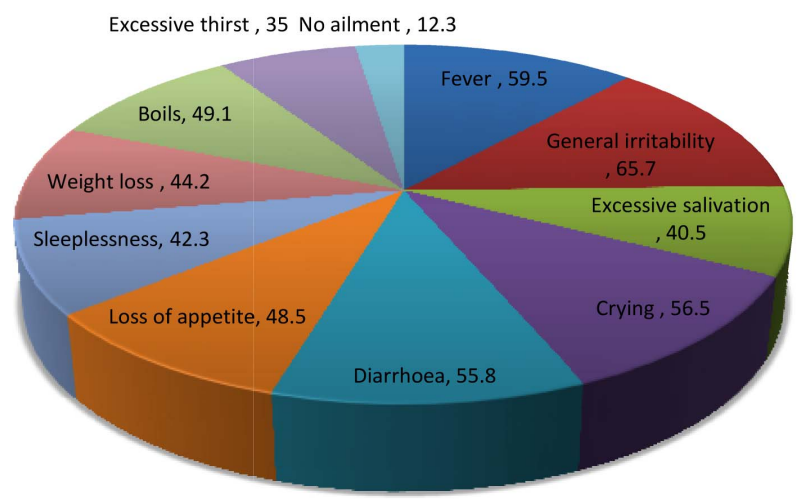

Figure 2. Perceived signs and symptoms of teething by the TBA's.

\section{DISCUSSION}

Asakitipi (2007) [20] investigating the diarrhea concept among Yoruba women in Ibadan metropolis in Nigeria

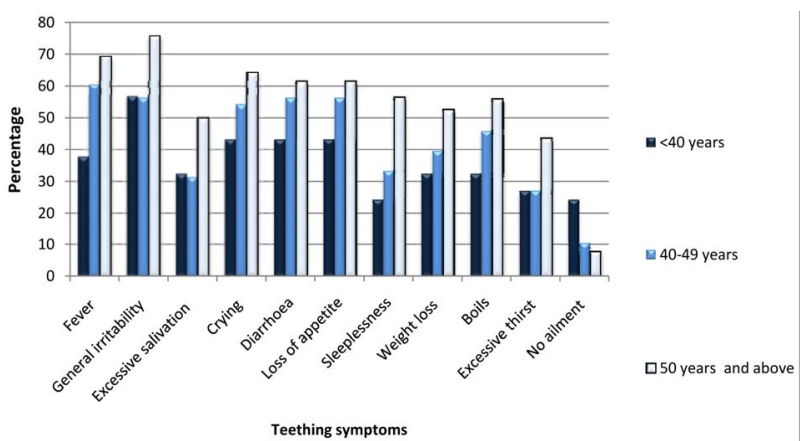

Figure 3. Teething symptoms by the age of the TBAs.

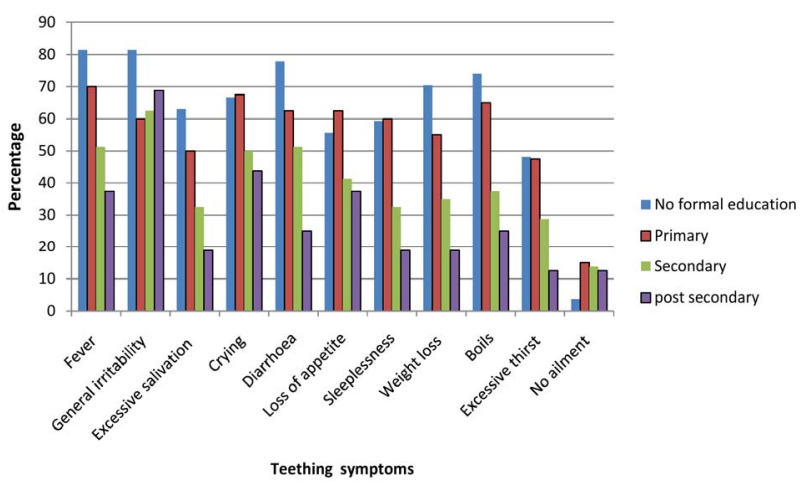

Figure 4. Teething symptoms by the educational level of the TBA's.

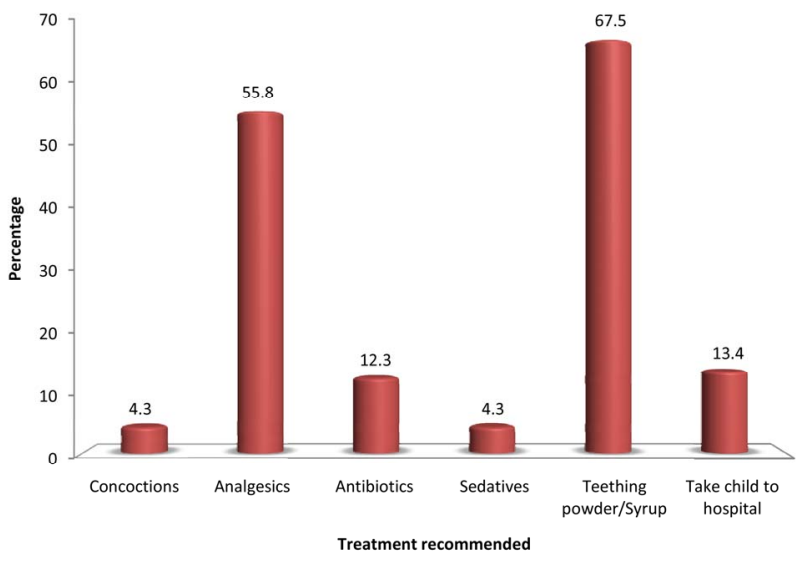

Figure 5. Treatment for teething as advised by the TBA's.

found out that it is widely believed that "Igbe-gbuuru" literally meaning loose stool is naturally caused by eruption of children's teeth. This teething process is believed usually to cause the body temperature to rise causing stomach upset and subsequently leading to diarrhea. It is also postulated traditionally that the teething process generates a lot of saliva in the mouth and the increased swallowing of the saliva contributes to the child's ill state by causing frequent passage of stool. This they also believe subsequently causes fever, loss of appetite, persistent crying, restlessness in infants [20].

Findings from this study have clearly revealed that 


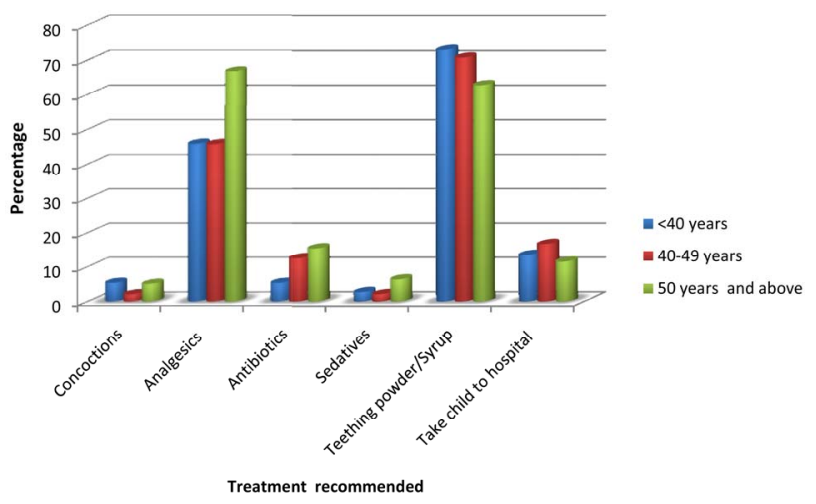

Figure 6. Treatment recommended by the age of the TBAs.

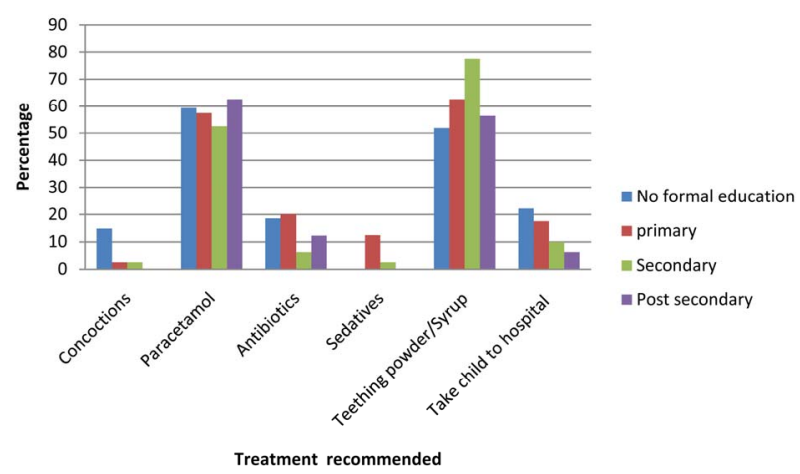

Figure 7. Treatment advised by the educational status of the TBA's.

Table 2. Treatment advised by the years of professional experience of the TBA's.

\begin{tabular}{cccc}
\hline & \multicolumn{3}{c}{ Years of experience } \\
\hline & $1-10$ & $11-20$ & 21 and above \\
Treatment advised & $(\mathrm{n}=75)$ & $(\mathrm{n}=57)$ & $(\mathrm{n}=31)$ \\
Traditional concoctions & $29(2.7)$ & $4(7.0)$ & $1(3.2)$ \\
Analgesics & $39(52.2)$ & $32(56.1)$ & $20(64.5)$ \\
Antibiotics & $9(2.0)$ & $7(12.3)$ & $4(12.9)$ \\
Sedatives & $2(2.7)$ & $0(0.0)$ & $5(6.1)$ \\
Teething powder/syrup & $51(68.0)$ & $43(75.4)$ & $16(51.6)$ \\
Take child to hospital & $12(16.0)$ & $4(7.0)$ & $6(19.4)$ \\
\hline
\end{tabular}

teething myths and misconceptions are prevalent among the traditional midwives in Ibadan as many associate teething with various ailments. This is in consonance with findings in certain surveys of some health workers $[10$, 21].

A possible explanation of this misunderstanding is that the timing of eruption of the primary incisors (6 - 12 months) coincides with the period of reduction of circulating maternal humoral immunity in the infant thus predisposes the child to a variety of infections [22]. Also, children at this stage are crawling resulting in placement of contaminated objects in their mouths, making them more prone to having diarrhea.
Many studies have concluded that no specific symptoms or cluster of symptoms can reliably predict the emergence of a tooth [23]. Symptoms that are associated to teething are not serious and presence of fever $\left(>38.5^{\circ} \mathrm{C}\right)$ or other clinically important symptoms are unlikely causes of teething [23]. Even though it is known that generally symptoms such as drooling, chin rash and irritability may be associated with the teething process, it is important that organic causes are ruled out. This was borne out from the research of Swann who reviewed 50 children admitted to hospital with a presenting complaint of teething. In 48 of these children, a medical condition was diagnosed including one case of bacterial meningitis [24].

Since many of TBA's associate teething with fever and diarrhea as causes naturally associated with teething the danger is that they will not advise affected mothers to seek proper medical consultation promptly for some of the ill children. The outcome of this study may be one of the contributing effects on the nation's child survival rate. Nigeria is a developing nation with a high infant mortality rate of 88/1000 live births (under 1 year) [25]. In a study in Guinea Bissau, Sodemann et al., [26] stated that only a third of parents with severely dehydrated children would seek medical help if they taught the dehydration was secondary to teething.

This study interestingly reveals that TBAs would recommend teething powder/syrup, analgesics and some would even recommend traditional concoctions to mothers as remedies for teething. Teething powder appears to be a popular remedy for teething among Nigerian mothers [27]. In the past teething powder contained high levels of mercury leading to poisoning, but they now contain essential oils which relieve irritation and gastric discomforts and restlessness [10]. In Nigeria teething mixtures (which mainly contain analgesics) seem to have gained increased popularity with the recent upsurge of local pharmaceutical companies. Unfortunately, there have been reports of contaminated teething syrups by local manufactures. In Nigeria in 2008, over 110 babies consumed "My Pikin" teething syrup out of which 84 died. Investigators found that the paracetamol-based mixture had been laced with an agent more commonly used as engine coolant-diethylene glycol. Batches of "My Pikin" were contaminated after the producer bought the chemicals from the slums of Lagos to save costs. It left the children with fever, convulsions, diarrhoea and vomiting, and the victims unable to urinate [12]. The authors of this study have personally observed that drug peddlers still sell illegal teething mixtures.

The use of analgesics would be advised by over half of the TBA's. While this may be desirable to keep body temperatures low in febrile conditions, a shortfall is that this may mask more serious underlying diseases giving a distorted clinical picture. 
The implication of the indiscriminate use of antibiotics among infants is that the child is at risk of developing adverse reactions such as hypersensitivity to the antibiotic and there is the potential for building of resistant bacterial strains [28]. The latter particularly happens as many give children insufficient dosages for inadequate length of time. Many of these antibiotics are purchased in patent medicine stores and some from drug peddlers in which expiry dates are sometimes not imprinted in their packaging.

It has also been been observed by the authors that among the local populace from the lower social class, tetracycline popularly called "capsule" is popularly given to babies to cure "teething diarrhea". Tetracycline is known to be taken up by calcifying tissues which lead to grayish discolouration of teeth. In study conducted by Aderinokun et al. [29], more than a third of 12-year-old school children in Idikan, a sub urbarn area in Ibadan had tetracycline stains on their teeth due to administration of tetracycline in infancy.

Some TBA's will recommend concoctions. Many of these are not scientifically tested with undetermined doses and content [30] as may be of danger to the health of the child. Documentations have revealed that the use of concoctions have sometimes led to some fatalities in children [31].

Various others folk remedies are used to treat teething among the Yoruba tribe in Nigeria. This includes using a special type of native black soap typically called "ose eyin" (teething soap) to bath these babies and palm kernel oil emulsion mixed with herbs and sometimes kerosene [10] is applied to the region of the anterior fontanelle on the skull of these children. Pregnant women too are advised to be given "aseje" (mixture of meat and various herbs laced with incantations) as a preventive measure for teething symptoms in their children, by traditional herbalists.

The implication of these findings of this study is that many TBAs will give wrong counsel to mothers and as such will not prompt them to seek medical help for their ill babies in time. This will encourage self medication which may result in resistant bacterial strains, hypersensitivity reactions and may lead to fatalities in infants

\section{CONCLUSIONS}

Misconceptions about teething in infants abound among the TBA's and symptoms associated with teething include fever (59.5\%), diarrhea (55.8\%) boils (49.1\%) and weight loss $(44.2 \%)$. Remedies recommended include teething powder/syrup (67.6\%), analgesics (55.8\%), antibiotics (12.3\%), concoctions and sedatives (4.3\%). Self medication recommended by the TBAs is worrisome as it can lead to undesirable effects thus having an implication on the child survival rate in Nigeria.
For such reason, there is an urgent need to educate the TBAs on such issues concerning teething in infants.

\section{REFERENCES}

[1] Carpenter, J.V. (1978) The relationship between teething and systemic disturbances. American Society of Dentistry for Children. Journal of Dentistry for Children, 45, 381384

[2] Ashley, M.P. (2001) Personal view. It's only teething... A report of the myths and modern approaches to teething. British Dental Journal, 191, 4-8.

[3] HM Stationary Office (1911) Registrar-Generals 74th annual report. Deaths from teething.

[4] Baykan, Z., Sahin, F., Bayazova, U., Ozçakar, B. and Baykan (2004) Experience of Turkish parents about their infants teething. Child: Care, Health and Development, 30, 331-336. doi:10.1111/j.1365-2214.2004.00431.x

[5] Owais, A.I., Zawaideh, F. and Bataineh, O. (2010) Challenging parents' myths regarding their children's teething. International Journal of Dental Hygiene, 8, 28-34. doi:10.1111/j.1601-5037.2009.00412.x

[6] Oyejide, C.O. and Aderinokun, G.A. (1991) Teething myths in Nigerian rural Yoruba communities. African Dental Journal, 5, 31-34.

[7] Anumudu, C.I., Christian, M.F., Okafor, Victor, N., Afolabi, K.A., Roseangela, I.N. and Nwagwu, M. (2007) Epidemiological factors that promote the development of severe malaria anaemia in children in Ibadan. African Health Sciences, 7, 80-85.

[8] Oshikoya, K.A., Idowu, M.D. and Senbanjo, O. (2008) Fever in children: Mothers' perceptions and their home management. Iranian Journal of Pediatrics, 18, 229-236.

[9] Oziegbe, E.O., Folayan, M.O., Adekoya-Sofowora, C.A., Esan, T.A. and Owotade, F.J. (2009) Teething problems and parental beliefs in Nigeria. The Journal of Contemporary Dental Practice, 10, 75-82.

[10] Bankole, O.O., Denloye, O.O. and Aderinokun, G.A. (2004) Attitude, beliefs and practices of some Nigerian nurses toward teething in infants. Odonto-Stomatologie Tropicale, 27, 22-26.

[11] Uti, O.G., Savage, K.O. and Ekanem, E.E. (2005) Maternal beliefs about infant teething. Journal of Community Medicine and Primary Health Care, 17, 61-64. doi:10.4314/jcmphc.v17i1.32429

[12] (2013) Tainted teething syrup kills 84 babies in Nigeria. www.independent.co.uk/news/world/africa/tainted-teething

[13] Naisho, J.N., Ongaya, L. and Musandu, J.O. (1989) A paper highlighting the role of TBAs in the implementation of primary health care. Kenya Nursing Journal, 17, 2628.

[14] Quiroga, R., Halkyer, P., Gil, F., Nelson, C. and Kristensen, D. (1998) A prefilled injection device for outreach tetanus immunization by Bolivian traditional birth attendants. Revista Panamericana de Salud Pública, 4, 20-25. doi:10.1590/S1020-49891998000700004

[15] Rashid, M., Tayakkanonta, K., Chongsuvivatwong, V., 
Geater, A. and Bechtel, G.A. (1999) Traditional birth attendants' advice toward breast-feeding, immunization and oral rehydration among mothers in rural Bangladesh. Women and Health, 28, 33-44. doi:10.1300/J013v28n03_03

[16] Temesgen, T.M., Umer, J.U., Buda, D.S. and Haregu, T.N. (2012) Contribution of traditional birth attendants to the formal health system in Ethiopia: The case of Afar region. The Pan African Medical Journal, 13, 15.

[17] Brennan, M. (1989) Training traditional birth attendants. Postgraduate Doctor, 11, 16-18.

[18] National Population Commission Oyo State (2006) Census.

[19] Oyo State Human Resources for Health Index (2010) Department of Planning Research and Statistics. Ministry of Health.

[20] Asakitikpi, A.E. (2007) An interrogation of diarrhoea concept among yoruba women in Ibadan metropolis, Nigeria. Nordic Journal of African Studies, 16, 64-74.

[21] Denloye, O., Bankole, O.O. and Aderinokun, G.A. (2005) Teething myths among community health officers. Odonto-Stomatologie Tropicale, 28, 19-22.

[22] Kakatkar, G., Nagarajappa, R., Bhat, N., Prasad, V., Sharda, A. and Asawa, K. (2012) Parental beliefs about children's teething in Udaipur, India: A preliminary report. Brazilian Oral Research, 26, 151-157. doi:10.1590/S1806-83242012000200011

[23] Tighe, M. and Roe, M.F.E. (2007) Does a teething child need serious illness excluding? Archives of Disease in Childhood, 92, 266-268. doi:10.1136/adc.2006.110114

[24] Swann, I.L. (1979) Teething complications, a persisting misconception. Postgraduate Medical Journal, 55, 24-25. doi:10.1136/pgmj.55.639.24
[25] UNICEF (2013) At a glance: Nigeria-Statistics. www.unicef.org/infobycountry/nigeria statistics.html

[26] Sodemann, M., Jakobsen, M.S., Mølbak, K., Martins, C. and Aaby, P. (1999) Management of childhood diarrhoea and use of oral rehydration salts in a suburban West African community. American Journal of Tropical Medicine and Hygiene, 60, 167-171.

[27] Ene Obong, H.N., Iroegbu, C.U. and Uwaegbute, A.C. (2000) Percieved causes and management of diarrhoea in young children by market women in Enugu State, Nigeria. Journal of Health, Population and Nutrition, 18, 97-102.

[28] Oshikoya, K.A., Njokanma, O.F., Chukwura, H.A. and Ojo, I.O. (2007) Adverse drug reactions in Nigerian children Paediatric and Perinatal Drug Therapy, 8, 81-88. doi:10.1185/146300907X199858

[29] Aderinokun, G.A., Lawoyin, J.O., Faseemo, V.O. and Bamgboye, S.M. (1994) Prevalence of tetracycline stained teeth amongst some school children in Ibadan, Nigeria. Nigerian Medical Practitioner, 27, 73-75.

[30] Fennell, C.W., Lindsey, K.L., McGaw, L.J., Sprag, S.G., Stafford, G.I., Elgoraschi, E.E., Grace, O.M. and van Staden, J. (2004) Assessing African medicinal plants for efficacy and safety: pharmacological screening and toxicity. Journal of Ethnopharmacology, 94, 205-217. doi:10.1016/j.jep.2004.05.012

[31] Eseigbe, E.E., Anyiam, J.O., Ogunrinde, G.O., Wammanda, R.D. and Zoaka, H.A. (2012) Clinical study health care seeking behavior among caregivers of sick children who had cerebral malaria in northwestern Nigeria. Malaria Research and Treatment. http://www.hindawi.com/journals/mrt/2012/954975/ 